\title{
LAS LEGUMINOSAS EN ALIMENTACIÓN ANIMAL
}

\section{LEGUMES IN ANIMAL NUTRITION}

\author{
Luis A. Rubio \\ Consejo Superior de Investigaciones Científicas \\ luis.rubio@eez.csic.es \\ Eduarda Molina \\ Consejo Superior de Investigaciones Científicas \\ molina@eez.csic.es
}

Cómo citar este artículo/Citation: Rubio, L. A. y E. Molina (2016). Las leguminosas en alimentación animal. Arbor, 192 (779): a315. doi: http://dx.doi.org/10.3989/arbor.2016.779n3005

Recibido: 08 marzo 2016. Aceptado: 06 mayo 2016.

RESUMEN: Desde el punto de vista de su uso en nutrición animal, pueden considerarse dos grupos de leguminosas: leguminosas-forraje (p. ej. la alfalfa), usadas en alimentación de rumiantes y leguminosas-grano (p. ej. habas, guisantes y altramuces), usadas esencialmente para aves y cerdos, y en menor medida para rumiantes. Las leguminosas-grano pueden sustituir parcial o totalmente a fuentes de proteínas tradicionales, de origen animal, como carne, huesos o harina de pescado en los piensos para animales, y representan una alternativa para las harinas de soja y otras oleaginosas. Su contenido en proteína es variable pero elevado (25-45 g/100 g materia seca). No obstante, la presencia de metabolitos secundarios (inhibidores de proteasas, saponinas, glucósidos, lectinas, taninos, alcaloides), así como sus altos niveles de fibra (polisacáridos no amiláceos), ha restringido el uso de leguminosas-grano en la alimentación de animales monogástricos (aves y cerdos) y, mucho más en la de rumiantes. Sin embargo, en la actualidad se está incrementando el interés por el uso de estas materias primas como alimentos funcionales, sobre todo en nutrición humana, pero también en nutrición animal, entre otras razones, como consecuencia de la prohibición del uso de proteína animal (harinas de carne y hueso), que tuvo lugar en la Unión Europea tras la crisis de la Encefalopatía Espongiforme Bovina. Para establecer el valor nutritivo de las leguminosas ha de prestarse especial atención a su composición en nutrientes, su contenido en energía y la digestibilidad de los aminoácidos. En rumiantes, es necesario establecer la degradabilidad en el rumen tanto de la proteína como de los aminoácidos individuales y de los carbohidratos, aspectos que determinan la utilización de nutrientes en este grupo animal, pero sobre los que existe muy poca información. En la actualidad, la perspectiva respecto a los taninos en las dietas de rumiantes está cambiando considerándose que pueden ejercer un efecto beneficioso. La soja es la semilla más utilizada como fuente de proteína en nutrición animal, pero el hecho de que haya de importarse en su mayor parte y que sea modificada genéticamente suponen dificultades para su utilización en la actualidad en Europa. Razones de índole medioambiental, sanitarias y productivas resultan en un progresivo interés en el cultivo de leguminosas en la UE.

PALABRAS CLAVE: Leguminosas-grano; monogástricos; rumiantes; valor nutritivo; metabolitos secundarios.
Copyright: (c) 2016 CSIC. Este es un artículo de acceso abierto distribuido bajo los términos de la licencia Creative Commons Attribution (CC BY) España 3.0.

ABSTRACT: From an animal nutrition point of view, legumes can be divided into two groups: fodder legumes (e. g. lucerne) mainly utilized in ruminant nutrition, and grain legumes (e. g. faba beans, peas, lupins) mainly used in bird and swine nutrition and, to a lesser extent, in ruminants. Grain legumes can partially or even totally replace traditional protein sources of animal origin such as meat, bone and fish meals. Moreover, they represent an alternative protein-rich feed ingredient for soybean meal and other oilseed meals. Their average protein content is variable but high (25-45 g / $100 \mathrm{~g}$ dry matter). However, the presence of secondary plant metabolites such as protease inhibitors, saponins, lectins, glycosides, tannins, and alkaloids, and their high levels of fiber (non- starch-polysaccharides) have restricted the use of legume-grains in monogastric (poultry and pigs) and ruminant feeding. In spite of this, the interest in, and the number of studies on, these resources as functional food products, especially in human, but also in animal, nutrition, are still on the increase. The ban on the use of animal proteins such as meat and bone meals, which took place in the EU as a consequence of the BSE crisis, has boosted the interest for the use of vegetable proteins, preferentially of local origin, in animal feeds. In order to establish the nutritional value of legumes, particular attention must be paid to their nutritional composition, energy content and amino acid digestibility. In ruminants, the degradability in the rumen of the protein, individual amino acids and carbohydrates are not well known and must be established. Approaches into the presence of tannins in ruminant feeds are currently changing due to their potential beneficial effects on nutrient degradation in the rumen, and on product quality or methane mitigation. Soybean is the raw material preferentially utilized as a protein source in animal feeds, but the great dependency on imported soybean and the fact that most is genetically modified are barriers to its utilization in the EU. In summary, environmental, health and productive considerations result in a growing interest in legume production in the EU.

KEYWORDS: Legume-seeds; monogastric; ruminant; nutritive value; secondary metabolites. 
Desde el punto de vista de la nutrición animal pueden considerarse dos grupos de leguminosas: las denominadas forrajeras y las leguminosas-grano. Entre las primeras se encuentran especies como alfalfa ( $\mathrm{Me}$ dicago sativa), trébol blanco (Trifolium repens), trébol rojo (Trifolium pratense) y otras, utilizadas tradicionalmente en la alimentación de los animales rumiantes como forraje. El segundo grupo incluye principalmente haba (Vicia faba), guisante (Pisum sativum) y diversas especies de altramuz (Lupinus spp), que se usan sobre todo en alimentación de aves y cerdos aunque también, en menor medida, en piensos para rumiantes. La importancia de las leguminosas-grano ha aumentado en los últimos años debido a la prohibición del uso de harinas animales en la fabricación de piensos en la Unión Europea como consecuencia de la crisis de la Encefalopatía Espongiforme Bovina (EEB). Por otra parte, en los últimos años se ha dado especial relevancia al hecho de que las leguminosas pueden contribuir a la llamada transición hacia una agricultura y sistemas agro-alimentarios sostenibles (Voisin et al., 2014). En general, las leguminosas-grano tienen un elevado contenido en proteína (25-45\%, dependiendo del género e incluso de la especie botánica) pero, además, presentan un elevado contenido en carbohidratos. Sin embargo, el uso de estas materias primas en alimentación animal, si bien está incrementándose, aún está lejos de los valores teóricamente posibles teniendo en cuenta su contenido en nutrientes. Por ello, uno de los retos científicos actuales en el ámbito de la Producción Animal es determinar los factores que limitan la eficiencia nutricional de las raciones basadas en leguminosas-grano.

\section{LIMITACIONES A SU VALOR NUTRITIVO: POSIBLES EXPLICACIONES}

Debido a que las semillas de leguminosas se utilizan fundamentalmente como concentrados proteicos, la utilización biológica de la proteína determina el uso de raciones basadas en leguminosas como la única o principal fuente de proteína. Existe una cierta información acerca de la utilización nutritiva y metabólica de la proteína de ese tipo de raciones en monogástricos. En general, puede decirse que la utilización neta de la proteína no sobrepasa el $65-70 \%$ cuando las leguminosas-grano constituyen la única fuente de proteína en la dieta, valores inferiores a los observados con proteínas de origen animal, que suelen superar el $90 \%$. Por esta razón, las recomendaciones de incorporación de leguminosas-grano a las raciones para monogástricos (cerdos, pollos de engorde) no suelen superar el 15\% (http://www.fundacionfedna.org/con- centrados_proteina_vegetal). Esta menor utilización de la proteína se acompaña a veces de alteraciones fisiológicas e incluso histológicas. Los factores que limitan la utilización nutritiva de las leguminosas en monogástricos pueden incluirse en dos grupos: presencia de substancias no-nutricionales y problemas relacionados con la utilización nutricional de la proteína.

1.- Presencia de substancias no-nutricionales (SNN). Las SNN son compuestos vegetales secundarios que ejercen una función defensiva de las plantas frente a plagas y parásitos vegetales, que no tienen una función específicamente nutricional, pero sí una determinada actividad biológica al ser ingeridos. En un primer momento, su interés en Nutrición, tanto humana como animal, se debió a la observación de que, en determinadas proporciones, pueden afectar negativamente a la utilización digestiva y/o metabólica de nutrientes. Actualmente, su interés científico está más centrado en los efectos biológicos de estos compuestos. El tipo y la concentración de las SNN varían mucho en las diferentes especies vegetales. Se hará mención aquí sucintamente de alguna de las más relevantes.

Los denominados inhibidores de Proteasas deben su efecto negativo a su capacidad para unirse al inhibidor de modo similar a como lo harían con el substrato, formando un complejo estable enzima-inhibidor debido a los numerosos enlaces complementarios que se producen en la zona de contacto (Liener y Kakade, 1980). En consecuencia, inhiben la actividad trípsica y quimotrípsica intestinal, lo que puede ocasionar una serie de alteraciones fisiológicas y productivas relacionadas con la pérdida endógena de aminoácidos. En habas (Vicia faba) y guisantes, la opinión más generalizada es que estos inhibidores pueden provocar hipertrofia del páncreas, pero tienen escaso efecto sobre el crecimiento de los animales (Wilson, Bentley y McNab, 1972a; Wilson, McNab y Bentley 1972b; Marquardt, Campbell y Ward, 1976).

Los fitatos son sales del ácido fítico (mio-inositol hexafosfato), se localizan únicamente en el cotiledón de las semillas y constituyen la principal reserva de fósforo aportando el $60-90 \%$ de este elemento. Forman compuestos insolubles en el tracto digestivo con cationes o proteínas (Reddy, Sathie y Salunkhe, 1982; Selle, Cowieson, Cowieson y Ravindran, 2012). En raciones prácticas para animales, a pesar de que estos compuestos pueden afectar negativamente a la utilización de algunos microelementos y proteínas, no existe consenso acerca de su efecto final sobre el crecimiento de los animales. Sin embargo, el uso de fitasas industriales (enzimas capaces de degradar fitatos 
y por tanto facilitar la absorción de fósforo) se ha generalizado en nutrición animal por razones medioambientales, ahorro en el uso de fósforo mineral en las raciones y prohibición del uso de harinas de hueso y carne en piensos (Selle et al., 2012).

Los taninos son compuestos polifenólicos solubles en agua, que están presentes en las plantas pudiendo ser hidrolizables o condensados (Jansman, 1993). Los taninos son astringentes y afectan considerablemente al valor nutritivo de las leguminosas por disminuir la palatabilidad de la ración y la digestión enzimática intestinal (Jansman, Huisman y van der Poel, 1993). Jansman et al. (1993) investigaron en los lechones los efectos de dietas con $300 \mathrm{~g} / \mathrm{kg}$ dieta de diferentes cultivares de haba y observaron una baja digestibilidad de la proteína para concentraciones de taninos de 1,0 a 2,3 g / kg de dieta. Flis, Sobotka, Purwin y Zdunczyk (1999) no encontraron efecto perjudicial sobre la tasa de crecimiento de cerdos (25-63 kg de peso corporal) alimentados con dietas que incluían 0,07 a 0,59 g de taninos / kg dieta. Por lo que respecta a los rumiantes, la planta de guisante ha sido bastante estudiada como forraje. Se ha utilizado en terneros en crecimiento como suplemento de dietas basadas en subproductos, con efectos mínimos sobre la digestibilidad de los nutrientes pero con una disminución importante de la ingesta (Soto-Navarro et al., 2004), que puede ser un síntoma de toxicidad debida a la presencia de algunos compuestos secundarios (D’Mello, 1992). Gelvin, Lardy, Soto-Navarro, Landblom y Caton (2004) observaron que la planta de guisante no afectaba ni a la fermentación ruminal ni a la digestibilidad de nutrientes en terneros. También se ha empleado la planta de guisante en dietas de corderos (Loe, Bauer, Lardy, Caton y Berg, 2004) para sustituir a la soja (Glycine max) sin que se afectase la producción del animal.

Las lectinas son proteínas de origen vegetal que aglutinan células y muestran especificidad de tipo anticuerpo para unirse a azúcares (Liener, Sharon y Lis, 1986). Se las ha definido como substancias de origen no inmune, que se unen específicamente a carbohidratos y aglutinan células o precipitan polisacáridos. Aunque existe controversia parece que su efecto tóxico se ejerce a través de su interacción con la mucosa intestinal. La unión de determinadas lectinas a los enterocitos se acompaña de lesiones histológicas (Pusztai, Croy, Grant y Stewart, 1983; Rubio, Brenes y Castaño, 1989; Rubio, Brenes y Castaño, 1990) y otras alteraciones en el recambio y división celular, lo que repercute negativamente no sólo en la absorción de otras substancias, sino también en la producción y funcionalidad de los enzimas digestivos producidos por los enterocitos. Si bien el efecto tóxico de algunas lectinas es muy acusado y explica, en gran parte, el bajo valor nutritivo de semillas como la judía (Phaseolus vulgaris) en estado crudo, en otros casos (habas, guisante, lenteja) estas proteínas no tienen un efecto tóxico demostrado. Por ejemplo, la incorporación a una ración testigo para ratas de una cantidad de lectina de haba o lenteja tres veces superior a la encontrada en la ración con semillas completas no afectó ni a parámetros productivos ni fisiológicos (Rubio et al., 1990; Cuadrado et al., 2002).

Diversas substancias biológicas, principalmente determinados carbohidratos y fibra, son parcial o totalmente no degradables en el tracto digestivo de los monogástricos debido a la ausencia del equipo enzimático necesario para su hidrólisis. Si bien no pueden considerarse SNN, estos compuestos han suscitado un gran interés en los últimos años en nutrición, tanto humana como animal, debido a sus posibles efectos sobre determinadas funciones fisiológicas. En atención al número de restos hidrocarbonados de su estructura se clasifican en oligo- y polisacáridos. Entre los primeros, los más estudiados son los azúcares relacionados con la rafinosa ( $\alpha$-galactósidos), que tienen en común la presencia en su molécula de uno o más grupos $\alpha$-D-galactopiranosilo. Los animales monogástricos y el hombre no poseen el enzima $\alpha$-galactosidasa, requerido para el desdoblamiento de estas substancias en el enlace $\alpha-1,6$. No obstante, los microorganismos del tracto digestivo, fundamentalmente los del intestino grueso, son capaces de degradar los compuestos mencionados dando lugar a ácidos grasos volátiles, $\mathrm{H}_{2}, \mathrm{CO}_{2}$ y metano. Esta producción de gas da lugar a flatulencia y osmolaridad, que confieren a estas sustancias características antinutritivas (Wiggins, 1984). Trabajos realizados en aves (Treviño, Centeno, Brenes, Yuste y Rubio, 1990) demuestran una muy escasa influencia de este tipo de oligosacáridos, presentes en las semillas de altramuz y guisante, sobre los parámetros productivos y la digestibilidad del almidón en aves. Su interés en nutrición se relaciona más bien con sus efectos sobre la composición de la microbiota intestinal, como se detalla más adelante. ${ }^{1}$

2.- Utilización nutricional de la proteína. A pesar de que las leguminosas grano se consideran esencialmente fuentes de proteína, su ingestión, tanto en animales como en humanos, promueve aumentos de la excreción intestinal de proteínas endógenas y del $\mathrm{N}$ en orina, cambios en las concentraciones de aminoá- 
cidos en plasma, modulación de los lípidos plasmáticos y colesterolemia y reacciones inmunes adversas, que generan alergias alimentarias. Por tanto, el valor nutritivo de las leguminosas está estrechamente ligado a la utilización nutricional de sus proteínas, la cual viene determinada fundamentalmente por su composición aminoacídica y por su digestibilidad intestinal.

Por un lado, hay que señalar que la proteína de las semillas de leguminosas es deficiente en algunos aminoácidos esenciales, principalmente cistina y metionina. Sin embargo, la incorporación de estos aminoácidos a raciones basadas en leguminosas tan sólo mejora ligeramente los índices productivos y fisiológicos de los animales. Así por ejemplo, la administración de suplementos de lisina no mejoró la ganancia de peso en cerdos alimentados con harina de semilla de altramuz, en comparación con la harina de soja (Batterham, Andersen, Lowe y Darnell, 1986).

Por otra parte, se ha prestado bastante atención a la digestibilidad de la proteína en leguminosas, considerándose que mientras la mayor parte de las proteínas de origen animal son rápidamente degradadas a aminoácidos en el tracto digestivo, las vegetales son generalmente más resistentes a la hidrólisis (Bressani y Elias, 1980). Esto se ha considerado un factor determinante de su bajo valor nutritivo (Romero y Ryan, 1978), aunque la información existente a este respecto es contradictoria. Con metodologías similares se ha estudiado la digestibilidad de la proteína de habas y guisantes, que es superior al 80\% (Gatel, 1992), valor suficientemente elevado. Por otra parte, se ha demostrado tanto in vivo como in vitro que las proteínas e incluso los aminoácidos de las leguminosas no son per se menos digestibles que otras de origen animal como lactoalbúmina o caseína (Rubio, 2000a; Rubio, Múzquiz, Burbano, Cuadrado y Pedrosa, 2002).

Hasta hace poco, se suponía que las proteínas de la dieta se degradan en el tracto gastrointestinal dando lugar a aminoácidos, que luego son absorbidos y utilizados, principalmente en el hígado, para sintetizar proteínas o formar parte de la reserva de aminoácidos del organismo. Este enfoque simplista ha cambiado en las últimas décadas, pues se ha observado que determinadas proteínas alimentarias, p. ej. lectinas e inhibidores de proteasas (ver arriba), pueden influir significativamente en una serie de funciones fisiológicas. Con objeto de profundizar en el estudio de su valor nutritivo, se han empleado fracciones purificadas de las proteínas de leguminosas-grano para poder discriminar los efectos debidos a la proteína de los debidos a otras fracciones químicas de la semilla como p. ej. carbohidratos o fibra. Sin embargo, son muy escasos los estudios realizados in vivo hasta el momento con proteínas purificadas, y la mayor parte se han centrado en proteínas globulares de soja y judía como la faseolina (Nielsen, 1991). Sgarbieri y Whitaker (1982) observaron, en ratas, que si bien la digestibilidad de la faseolina es del $80-90 \%$ su presencia en la dieta daba lugar a una hipersecreción, en el intestino, de material insoluble rico en $\mathrm{N}$. La sustitución de un $60 \%$ de la lactoalbúmina por proteína purificada de haba produjo alteraciones fisiológicas y productivas similares a las observadas con semillas enteras de esta leguminosa (Rubio, Grant, Bardocz, Dewey y Pusztai, 1991), y algo similar se produjo con otras proteínas de leguminosas (Rubio, Grant, Cavallé, Martínez-Aragón y Pusztai, 1994; Rubio, Grant et al., 1998). Ello sugiere que la fracción principalmente responsable de la menor retención de $\mathrm{N}$ en raciones basadas en harina de haba sea, probablemente, su proteína de almacenamiento, y no otros factores, como las SNN. Aubry y Boucrot (1986), en ensayos in vivo realizados en ratas, mostraron que proteínas de leguminosas como la vicilina y legumina del guisante tienen una absorción intestinal tan elevada como la de la caseína. Sin embargo, el valor nutricional de las dietas con proteínas purificadas de leguminosas o incluso con semillas enteras, que contienen poca o ninguna cantidad de SNN, es inferior a la de las dietas control a pesar de que tanto la digestibilidad fecal como la ileal o el $\mathrm{N}$ fecal no diferían de los valores del grupo control (Rubio et al., 1991; Rubio et al., 1994; Rubio, Grant et al., 1998; van der Poel, Dellaert, Norel y Helpster, 1992). Estos resultados sugieren que las globulinas de leguminosas no desnaturalizadas son per se altamente digestibles en el intestino delgado, y por tanto, la menor digestibilidad de las proteínas, cuando se presenta en la semilla entera, puede deberse a otros factores como la presencia de SNN o algún tipo de complejo fibra-proteína (Jezierny et al., 2011).

Sin embargo, a pesar de su alta digestibilidad, la inclusión de globulinas purificadas de altramuz, haba, garbanzo o soja en raciones para ratas tuvo un importante efecto sobre el rendimiento nutricional provocando disminución en el ritmo de crecimiento de los animales (Rubio, Grant, Scislowsky et al., 1995; Rubio, Grant et al., 1998). A excepción de las globulinas de soja, este menor rendimiento fue acompañado por un aumento significativo de la excreción de urea en la orina. Dado que la urea es el producto final del catabolismo proteico en los mamíferos, valores plasmáticos de urea más elevados se asocian con alteraciones en el metabolismo de las proteínas, concretamente con el aumento de su degradación. Esto da lugar a una pér- 
dida de $\mathrm{N}$ en la orina y a una menor retención de $\mathrm{N}$ con valores netos de utilización de proteínas también menores, incluso cuando se suplementa la dieta con aminoácidos esenciales (Rubio, 2000a).

Algunos estudios se han orientado hacia la determinación de los perfiles de aminoácidos en el plasma de animales alimentados con raciones a base de leguminosas. Las concentraciones plasmáticas de glicina, histidina y arginina fueron más elevadas en ratas alimentadas con dietas basadas en harina de habas, altramuces, garbanzos y soja o sus respectivas proteínas purificadas cuando se comparaban con los controles, mientras que los niveles de treonina, leucina y lisina eran más bajos. Tirosina, asparagina, glutamina y serina no se vieron afectados significativamente, mientras que alanina, metionina, isoleucina, fenilalanina y ornitina no siempre se afectaban (Rubio, Grant, Daguid, Brown y Pusztai, 1999). Una menor disponibilidad de lisina en ratas y cerdos alimentados con altramuz blanco (Lupinus albus) también fue observada por Batterham et al. (1986). Por lo tanto, los efectos sobre las concentraciones de aminoácidos en plasma, al menos para la lisina, son rápidos y probablemente independientes de la suplementación con aminoácidos deficientes en la dieta. Como resultado, la mezcla de aminoácidos disponibles para la síntesis de proteínas en los tejidos en un momento dado, particularmente en el hígado, podría estar desequilibrada y, en consecuencia, disminuir la tasa de síntesis de proteínas aumentando el catabolismo de aminoácidos (Benevenga, Gahl, Blemings, 1993). Utilizando cultivos de células Caco-2 se ha observado que los aminoácidos de las proteínas de leguminosas son absorbidos a ritmos diferentes que los de otras proteínas de origen animal como la caseína (Rubio y Seiquer, 2002). Podrían, por tanto, producirse diferencias en las proporciones de aminoácidos en sangre como consecuencia de la ingestión de diferentes proteínas, lo que podría dar lugar a diferencias en las tasas de síntesis proteica en los tejidos, las cuales a su vez tienen un efecto directo sobre el crecimiento de los animales. De hecho, existe información que sugiere un efecto fisiológico de las proteínas de leguminosas sobre el metabolismo de las proteínas (Rubio, 2000a). Finalmente, determinados efectos de las leguminosas sobre el sistema inmune también podrían explicar, al menos en parte, su menor valor nutritivo, aunque los mecanismos implicados en estos efectos inmunológicos no están claros y los alérgenos no han sido identificados (Dréau, Lallès, Philouze-Rome, Toullec y Salmon, 1994; Lallès, Dréau, Féménia, Parodi y Toulec, 1996; Rubio, Rodríguez, Fernández y Crespo, 2004).

\section{LAS LEGUMINOSAS COMO ALIMENTOS FUNCIONALES}

Tanto para humanos como para animales superiores, el acto de nutrirse puede considerarse actualmente como un proceso de interacción dinámica organismo-microbiota-alimento. Estos tres agentes, cada uno de ellos muy complejo, se modifican e interactúan de manera diferente y continua. Este carácter dinámico, en el que intervienen un gran número de factores, muchos de los cuales aún son desconocidos, hace que muchos procesos nutricionales no sean fáciles de comprender con la información actual.

El estado actual de la cuestión, en relación con algunos aspectos novedosos que han surgido en los últimos años en el ámbito de la Nutrición, permite comprender hasta qué punto esta interrelación es estrecha. La relación organismo-alimento ha sido la más estudiada, ya que a ella se ha dedicado casi exclusivamente la investigación en Nutrición desde el S. XVIII, momento en que puede datarse su inicio como ciencia. Aspectos relativamente bien conocidos son la composición de los alimentos, la digestibilidad, utilización digestiva y metabólica de nutrientes y energía, etc. Sin embargo, durante los últimos decenios se han ido acuñando una serie de términos referidos a nuevos conceptos, entre los que pueden citarse "alimentos funcionales", "nutracéuticos", "nutrigenómica", etc. Todos ellos aluden a determinados efectos, no estrictamente nutricionales, de los alimentos sobre la fisiología o, incluso, sobre el genoma del organismo que los consume. Estos efectos se deben a determinados compuestos biológicamente activos que se encuentran en los alimentos y que no ejercen un efecto nutricional concreto ya que no son utilizados para la formación de tejido, suministro de energía, aporte de nutrientes, etc. Sin embargo, son capaces de modificar la fisiología digestiva, la estructura histológica, la composición de la microbiota intestinal, el funcionamiento del sistema hormonal e inmunitario, etc.

El concepto de alimento funcional nació en los años 80 del siglo pasado en Japón, y apareció publicado y descrito por primera vez en 1993 en un artículo titulado "Japón explora la frontera entre alimento y medicina" (Arai, 2002). Los efectos observados tras la ingestión de determinadas proteínas alimentarias, presentes en las semillas de leguminosas, como las proteínas de almacenamiento, inhibidores de proteasas, lectinas, etc. permiten considerar a estos alimentos como funcionales. Desde hace tiempo se reconoce que la sustitución en la dieta de proteína animal por vegetal disminuye los niveles plasmáticos de colesterol y triglicéridos aunque no está claro a qué 
componente(s) se debe tal efecto. Sin embargo, uno de los principales candidatos es un determinado grupo de proteínas de almacenamiento, la llamada subunidad $\alpha^{\prime}$ de la fracción 75 de la soja, cuyos efectos, tanto in vivo como in vitro, han sido bien estudiados (Lovati et al., 1992). Algunos trabajos (Caligari et al., 2006) sugieren que la proteína de almacenamiento del altramuz podría ejercer un efecto antiproliferativo en el intestino grueso, lo que, de confirmarse, abriría interesantes líneas de trabajo. Por otra parte, proteínas de diferente estructura podrían digerirse y absorberse de modo diferente, lo que daría lugar a efectos diferentes sobre el hígado y, consecuentemente, influir sobre determinados parámetros o producir efectos nutricionales diferentes (Rubio y Seiquer, 2002). Resultados recientes de nuestro grupo (Utrilla et al., 2015) han mostrado un efecto antiinflamatorio de albúminas del guisante a nivel del colon en ratones, y otros datos no publicados sugieren un efecto directo de estas mismas proteínas sobre la absorción de glucosa en adipocitos. Es claro, por tanto, que la relación animal-alimento es más compleja de lo que se suponía hasta hace unos años, ya que no se limita a la mera incorporación de nutrientes, sino que implica una modificación, por parte de componentes del alimento, de funciones fisiológicas a veces bastante alejadas de las estrictamente nutricionales.

El estudio de la relación organismo-microbiota ha experimentado un rápido avance en los últimos años debido al desarrollo de las técnicas moleculares. El intestino de los animales superiores y del hombre alberga 10-100 mil millones de microorganismos por gramo de contenido, y en el tracto gastrointestinal total el número de microorganismos excede en 10 veces el de células somáticas del organismo. La microbiota gastrointestinal puede considerarse como un órgano microbiano, que contiene 100 veces más genes que el organismo somático y que interacciona constantemente con el soma de un modo mutualista. El conjunto de la microbiota intestinal puede considerarse como un auténtico biorreactor capaz de degradar un gran número de substancias de otro modo inutilizables (polisacáridos, algunas fracciones proteicas y amiláceas, etc.) para proporcionar, a cambio, nutrientes como ácidos grasos, vitaminas, etc. al hospedador (Bäckhed, Ley, Sonnenburg, Peterson y Gordon, 2005). Todo este complejísimo sistema, que mantiene en equilibrio no menos de 800 especies de microorganismos, no sólo proporciona nutrientes sino que modula permanente el funcionamiento del digestivo mediante al menos dos mecanismos: por su acción directa sobre las fracciones alimentarias y a través de los efectos producidos por las substancias generadas por la microbiota. Estas substancias influencian tanto su propio metabolismo como el del animal al ser absorbidas. El organismo hospedador ejerce una acción permanente sobre la microbiota por medio de las secreciones intestinales, el sistema inmunitario, la estructura antigénica, etc. Esta estructura antigénica está determinada genéticamente, lo que proporciona especificidad a la flora no sólo para cada especie animal sino también para cada individuo. En condiciones sanitarias y de alimentación normales, las principales funciones de la microbiota consisten en proporcionar una barrera sanitaria eficaz contra patógenos, estimular el desarrollo y funcionalidad del sistema inmune y aportar determinados nutrientes (vitaminas, ácidos grasos) (Roberts et al., 2015). Esta relación organismo-microbiota puede modificarse, y probablemente modularse, mediante manipulaciones en la dieta. Determinadas leguminosas pueden ser herramientas útiles en esta modulación.

Por lo que se refiere a la relación alimento-microbio$t a$, en los últimos años se ha prestado gran atención a las posibilidades terapéuticas de la suplementación de raciones o alimentos con los llamados probióticos, prebióticos y simbióticos. Los primeros están constituidos, fundamentalmente, por células microbianas viables; los prebióticos son substancias como por ejemplo azúcares naturales o sintéticos (lactulosa, fructooligosacáridos, otros oligosacáridos) que no son digeridas en el intestino delgado y suponen un aporte nutritivo en el intestino grueso para especies microbianas beneficiosas como lactobacilos y bifidobacterias. Los simbióticos son mezclas de pro y prebióticos. Que en Scopus se puedan encontrar 17.820 referencias y más de 820 patentes referidas a "prebióticos o probióticos", tan sólo en los últimos 10 años, es indicativo del interés que este tipo de estudios está suscitando. El posible efecto beneficioso de pro- y prebióticos se fundamenta en la hipótesis de que un mayor desarrollo o estabilidad de determinadas especies bacterianas, especialmente las llamadas bacterias lácticas, puede conllevar la limitación o supresión del desarrollo de otras potencialmente patógenas como enterobacterias, clostridios y Escherichia coli (Fuller, 1992). El mecanismo por el que las bacterias lácticas limitan el crecimiento de otras potencialmente patógenas parece basarse en la producción, por parte de aquéllas, de antibióticos específicos pero también de ácidos acético y láctico, lo que hace descender el $\mathrm{pH}$ del medio intestinal, que se hace menos favorable al crecimiento de otros microorganismos, especialmente de coliformes (Modler, Mckellar y Yaguchi, 
1990). Dado que los componentes de la interacción alimento-intestino-microbiota son interdependientes, las modificaciones en uno de ellos repercuten, en mayor o menor medida, en todo el proceso de digestión y absorción. Estas modificaciones pueden obtenerse por medio de la inclusión en la dieta de determinadas substancias (lectinas, glucoconjugados, polisacáridos) de composición y actividad o propiedades conocidas. De este modo, el grupo del Dr Pusztai (1990) acuñó el término probiosis química para describir un procedimiento diseñado para modificar la estructura y función de la superficie de absorción de la pared intestinal por medio de aditivos naturales (lectinas, glucoconjugados), que a través de mecanismos competitivos o modificando la expresión de receptores intestinales, puede reducir la incidencia de bacterias potencialmente patógenas y/o incrementar el desarrollo de las potencialmente beneficiosas.

En la actualidad es muy relevante el estudio de los efectos que determinados polisacáridos naturales pueden ejercer sobre el equilibrio de la flora intestinal, no sólo por razones de tipo nutricional, sino también por la información que se puede generar en relación con la interrelación microbiota intestinalcomposición química del alimento (Salminen et al., 1998). Controlar eficazmente la ecología intestinal en diferentes circunstancias requiere conocer los mecanismos que controlan dicho equilibrio. Por ejemplo, es sabido que en la patogenia de la enfermedad de los edemas porcina, causada por E. coli, la colonización de la pared intestinal es un paso crucial (Imberechts, Degreve y Lintermans, 1992), por lo que las modificaciones de las condiciones intestinales que dificulten este paso disminuirían el riesgo de los animales a contraer la enfermedad.

Los estudios relacionados con los efectos de las fracciones fibrosas de los alimentos de origen vegetal se han multiplicado en los últimos años en nutrición humana y animal. En el primer caso, por la observada relación inversa entre la cantidad de fibra alimentaria en la dieta y la incidencia de determinados tipos de cáncer desde los trabajos de Burkitt, Walker y Painter (1972), y en nutrición animal debido a sus implicaciones productivas. De entre los componentes principales de la ración, proteína, grasa y carbohidratos, éstos últimos conforman el grupo más heterogéneo y peor conocido en cuanto a sus efectos fisiológicos, aunque constituyen más del $50 \%$ de la ración. Entre ellos, el almidón ha sido estudiado en mayor profundidad por su importancia energética, pero no así las fracciones incluidas en lo que se ha denominado fi- bra dietética, que incluye polisacáridos no amiláceos (PNA) y lignina (Cummings, 1981). Mientras la lignina está constituida por polímeros de fenil-propano y es indigestible en intestino delgado y grueso, los PNA engloban fundamentalmente celulosas, hemicelulosas y pectinas, cuya composición, propiedades químicas y comportamiento en el tracto digestivo son muy variados. Hasta hace unos años se consideraba a estas fracciones prácticamente inertes en el proceso digestivo en monogástricos. Por el contrario, actualmente los efectos atribuidos a los PNA se engloban en áreas muy diversas y de gran importancia tanto desde un punto de vista fisiológico como metabólico: modificaciones en el tránsito intestinal y volumen fecal, adsorción de minerales, alteraciones en la digestión y absorción de nutrientes (proteína, grasas), influencia sobre el metabolismo de grasas (colesterol, triglicéridos) y azúcares (glucosa, insulina), efectos sobre la flora y determinados tipos de cáncer (colon). Todos estos aspectos llevan a considerar a estas substancias como integrantes de los alimentos funcionales (Salminen et al., 1998). Sin embargo, los mecanismos implicados en todos estos efectos son complejos y en gran medida desconocidos (Furda y Brine, 1990).

En el caso concreto de las leguminosas, se ha descrito que raciones basadas en harina de altramuz dulce (Lupinus angustifolius) pueden ejercer un efecto significativo sobre la población microbiana intestinal (Rubio, Grant, Spencer y Pusztai, 1995; Rubio, Brenes, Cutuli y Setién, 1998). Se han descrito efectos significativos en aves y ratas (Rubio, Grant, Scislowsky et al., 1995) sobre las concentraciones hemáticas de colesterol y triglicéridos en animales alimentados con semilla completa de altramuz o sus fracciones fibrosas. La inclusión de harina de leguminosas en raciones para cerdos en crecimiento dio lugar a incrementos en la microbiota beneficiosa (Rubio y Peinado, 2015), efecto probablemente relacionado con la presencia de oligo- o polisacáridos en las leguminosas utilizadas.

Los PNA pueden servir como fuente nutritiva para las bacterias lácticas, cuyo crecimiento inhibiría a su vez el de coliformes. Esta hipótesis está de acuerdo con otros estudios (Mathew et al., 1993) en los que la inclusión de un galactano (un tipo de PNA) en raciones para cerdos en crecimiento dió lugar a descensos en el $\mathrm{pH}$ y E. coli K88 enteropatógeno en el intestino delgado sin variaciones en los índices productivos. Si bien estos autores no encontraron un efecto sobre la población intestinal de lactobacilos, conviene señalar que los arabinogalactanos de las paredes celulares vegetales constituyen fuentes energéticas para Bifidobacterium 
spp (Salyers, 1979), grupo considerado beneficioso. Las substancias no nutricionales, debido a su posible aplicación en beneficio del hospedador, han perdido su denominación tradicional (factores antinutritivos) y tienden a denominarse SNN en función de la actividad biológica que presentan in vivo, lo que permite su consideración como posibles alimentos funcionales.

Así, los inhibidores de proteasas se están explorando en relación con dos posibles aplicaciones: a) agronómicas, como elementos defensivos contra parásitos o plagas vegetales, b) como agentes anticancerígenos. En relación con la primera aplicación hay que tener en cuenta el prácticamente indefinido abanico de posibilidades abierto actualmente por la biotecnología. En este momento es posible la transferencia de cualquier parte del genoma de un ser vivo a otro sin barreras (transgénesis) dando lugar a los llamados organismos genéticamente modificados (OGM). Ello ha abierto, en el caso que nos ocupa, la posibilidad de incorporar elementos defensivos nuevos para una especie vegetal determinada. Por ejemplo, la incorporación al tomate de los genes capaces de codificar la síntesis de inhibidores de proteasas (KTI) (o lectinas como GNA) confiere a aquel una defensa muy eficaz contra la larva de Heliothis virescens (Boulter, Gatehouse, Gatehouse y Cox, 1985; Christou, Capell, Kohli, Gatehouse y Gatehouse, 2006). Si bien estas técnicas abren enormes posibilidades, hay que señalar: i) que no está demostrada la inocuidad de las técnicas de transgénesis en organismos de interés nutricional (Rubio, 2000b), y ii) la existencia de datos que sugieren que los efectos debidos a la transgénesis no se limitan a los obtenidos por la técnica misma (Ewen y Pusztai, 1999). Ello supone que la modificación del genoma en un lugar determinado puede afectar el funcionamiento del genoma en otros lugares y provocar cambios en la síntesis proteica, lo que a su vez puede alterar los efectos (nutricionales) producidos por el organismo que ingiere un determinado alimento. En cuanto a la segunda posible aplicación, investigaciones llevadas a cabo en los últimos 25 años han relacionado la capacidad inhibidora del inhibidor de quimotripsina (BBI) con un claro efecto anticancerígeno tanto in vivo como in vitro (Kennedy, 1993; Clemente y Arqués, 2014). ${ }^{2}$

Se ha relacionado a los fitatos con la inhibición del crecimiento de células tumorales. La incorporación de la sal sódica de IP6 en el agua de bebida (2\%), antes y después de la aplicación de un carcinógeno, ha dado lugar a disminuciones muy significativas tanto en el número como en el tamaño de tumores de colon, hígado y mama en roedores, sin ningún efecto tóxico en con- troles (Shamsuddin y Ullah, 1989; Ullah y Shamsuddin, 1990). Por otra parte, ensayos in vitro con cultivos de células (MCF7 del carcinoma mamario humano, HT29 del carcinoma de colon humano) han demostrado una relación inversa entre la dosis de IP6 utilizada y el crecimiento de células tumorales (Shamsuddin, 1995). Además, hay que señalar otros efectos sobre la lipidemia y la arterioesclerosis. Esta actividad se relaciona con la posible acción de los fitatos en la regulación de la relación $\mathrm{Zn} / \mathrm{Cu}$ en animales hiperlipidémicos, lo que resultaría en un descenso de los valores de lípidos en sangre. Por otra parte, el efecto antioxidante de los fitatos se ha relacionado con una inhibición de la peroxidación de lípidos catalizada por metales, lo que daría lugar a una menor aparición de lesiones aórticas y, por tanto, de ateromas (Kumar, Sinha, Makkar y Becker, 2010).

También las lectinas se han investigado en relación con posibles efectos biológicos beneficiosos. Muchas de las lectinas estudiadas hasta este momento muestran una acusada capacidad mitogénica (judía, Phaseolus vulgaris, PHA) o antimitogénica (tomate, Lycopersicon esculentum, LEL). Por tanto, se está investigando el potencial de estas substancias para acelerar la maduración celular y como anti-carcinogénicos (Pusztai, 1998). También se relaciona a las lectinas con la modificación de la flora intestinal. Parece claro que el efecto de las lectinas está relacionado con la modificación, por parte de la lectina, de la estructura antigénica de la mucosa intestinal, que incrementa la capacidad de E. coli para adherirse a la pared intestinal mediante sus propias lectinas y crecer. Por tanto, parece posible modificar la mucosa intestinal para que sea más o menos receptiva a determinados tipos de gérmenes. Estudios con PHA y GNA (lectina de Galantus nivalis) han demostrado que este efecto es posible al menos en condiciones experimentales (Pusztai, Grant et al., 1993) muy probablemente debido al bloqueo, por parte de GNA, de los posibles lugares de anclaje de $E$. coli en la mucosa digestiva. El estudio conjunto de la estructura intestinal, la ecología microbiana y la actividad in vivo de las lectinas puede abrir interesantes posibilidades para la manipulación de la flora digestiva, con posibles consecuencias de gran importancia práctica tanto sanitarias como productivas (Pusztai, Grant, King, Clarke, 1990). Por otra parte, algunas lectinas especialmente activas son capaces de traspasar la barrera intestinal, acceder al torrente circulatorio y alcanzar órganos muy alejados del sistema digestivo modificando considerablemente el metabolismo lipídico, hidrocarbonado y proteico del animal ocasionando incluso la muerte en pocos días. El mecanismo de internalización parece ser la endocitosis en los enterocitos y transporte a la parte basal de la cé- 
lula por donde accede al torrente circulatorio debido a su resistencia a la hidrólisis en los lisosomas. El estudio de la estructura química de la molécula de lectina está desvelando las secuencias de aminoácidos responsables tanto de su actividad tóxica como de su capacidad para atravesar la mucosa intestinal. Debido, además, a su especificidad por determinados azúcares complejos, que forman parte de las membranas celulares, en este momento se estudia la posibilidad de utilizar estas substancias para vehicular fármacos orales hacia determinados lugares del organismo (Pusztai, Kocsis, Grant, Ewen y Bardocz, 1993).

El estudio de éstas y otros tipos de substancias presentes en los alimentos requiere una atención científica especial ya que pueden facilitar no sólo el diseño de mecanismos capaces de modificar el proceso nutritivo en beneficio del estado sanitario o productivo del consumidor, sino también la comprensión del proceso nutritivo en sí mismo.

\section{ALGUNOS ASPECTOS DEL USO DE LEGUMINOSAS EN LA ALIMENTACIÓN DE RUMIANTES}

Las leguminosas forrajeras como la alfalfa y los tréboles se han utilizado tradicionalmente en la alimentación de los animales rumiantes (Wilkins y Jones, 2000). También la planta de guisante (Pisum sativum) se ha utilizado como forraje en terneros en crecimiento, formando parte de dietas basadas en subproductos, con efectos mínimos sobre la digestibilidad de los nutrientes pero con una disminución importante de la ingesta (Soto-Navarro et al., 2004). La disminución de la ingesta puede ser un síntoma de toxicidad debida a la presencia de algunos compuestos secundarios (D’Mello, 1992). Gelvin et al. (2004) observaron que la planta de guisante, utilizada como forraje, no afectaba ni a la fermentación ruminal ni a la digestibilidad de nutrientes en terneros. También se ha empleado la planta de guisante en dietas de corderos (Loe, Bauer, Lardy, Caton y Berg, 2004) para sustituir al maíz hasta $450 \mathrm{~g} / \mathrm{kg}$ DM sin que se afectase la producción del animal. Además, la velocidad de degradación de semillas como veza (Vicia sativa), yero (Vicia ervilia), guisante, altramuz y haba es alta habiéndose observado que tras 24 horas de incubación en el rumen de corderos desaparecía más del $88 \%$ de la semilla salvo en el caso de la veza, cuya degradabilidad para ese tiempo de incubación fue menor (Aguilera, Bustos y Molina, 1992). González y Andrés (2003) determinaron, así mismo, degradabilidades ruminales de materia seca $(58,8$ a $69,2 \%$ ) y de proteína $(69,3$ a $80,3 \%)$ relativamente altas en carneros.
Las semillas de leguminosas podrían ser un suplemento de interés para alimentos de baja calidad como los disponibles en el Mediterráneo. La suplementación de hoja de olivo con cebada y habas grano incrementa, tanto en ovino como en caprino, la excreción de derivados púricos (Yáñez Ruiz, Moumen y Molina, 2004), índice de la síntesis de proteína microbiana promovida por una determinada dieta en el rumen. La proteína sintetizada en el rumen es la fracción mayoritaria (70\%) de la proteína disponible en el intestino para este tipo de animales a partir de la cual se atienden las necesidades que el animal tiene de este nutriente. Las semillas de leguminosas, sin embargo, se han utilizado poco en la alimentación de rumiantes y la información disponible acerca de su valor nutritivo es escasa aunque tras la prohibición del uso de harinas de origen animal en la alimentación del ganado y los problemas asociados al uso de harina de soja (importada, y modificada genéticamente y asociada a la aparición de alergia), el uso de semillas de leguminosas autóctonas es objeto de un creciente interés. Las leguminosas no solo son fuentes importantes de proteína y carbohidratos sino que presentan una serie de ventajas ecológicas: su cultivo aporta nitrógeno al suelo (Caballero, 1999) y su uso en la dieta de los rumiantes reduce la excreción de contaminantes nitrogenados en las excretas del animal puesto que su contenido en proteína es inferior al de las harinas de carne. El valor nutritivo de las semillas de leguminosas en rumiantes se conoce poco y es muy escasa la información de que se dispone sobre aspectos que determinan el valor proteico de la dieta en este grupo animal, como son la degradabilidad ruminal de la proteína, la digestibilidad intestinal de la fracción no degradada en rumen o la composición en aminoácidos de la proteína no degradada en rumen. Además, las semillas de leguminosas no solo son una fuente de proteína sino también de carbohidratos (Abreu, Carulla, Lascano, Díaz, Kreuzer y Hess, 2004), fracción cuya utilización en el rumen se conoce aún menos que la de la proteína (Goelema, Spreeuwenberg, Hof, van der Poel y Tamminga, 1998).

Dado que, como se ha indicado anteriormente, las leguminosas contienen compuestos secundarios denominados SNN en cantidades elevadas, y que estos compuestos pueden limitar la utilización nutritiva de la proteína se han ensayado diversos tratamientos previos a la inclusión de las semillas en la dieta del rumiante: tostado (Murphy y McNiven, 1994), extrusión (Benchaar, Vernay, Bayourthe y Moncoulon, 1994), autoclavado (Aguilera et al., 1992). El autoclavado de las semillas disminuye la fracción soluble y la velocidad de degra- 
dación en el rumen de ovino de la proteína, lo que puede tener efectos beneficiosos al incrementar la cantidad de proteína no degradada y que pasa al intestino delgado para atender a los requerimientos del animal. El autoclavado disminuye también la degradabilidad efectiva de las semillas aunque la magnitud del efecto depende del tipo de semilla considerado. Dicho efecto es muy importante para el guisante y el altramuz, moderado para habas y yeros y apenas se manifiesta en el caso de la veza. Aguilera et al. (1992) establecieron, utilizando marcadores, que la velocidad de paso (factor que determina la ingesta en rumiantes) de las semillas a través del rumen de corderos variaba entre 0,0154 y 0,022 por hora dependiendo del nivel de alimentación de los animales.

En un estudio realizado con distintas variedades de habas (Alameda, Palacio, Baraka) o de garbanzo (Fardon y Zegri), se observó que la composición química de las variedades de cada género es muy similar y las habas contienen más taninos y menos grasa que el resto de esas semillas (Yáñez-Ruiz, Martín-García, Weisbjerg, Hvelplund y Molina-Alcaide, 2009). También la degradabilidad de la proteína y la digestibilidad intestinal de la fracción de proteína no degradada en el rumen son similares para las distintas semillas, con la excepción del altramuz cuya velocidad de degradación es superior a la del resto de esas semillas. Utilizando fermentadores de flujo continuo estos autores establecieron que las habas y guisantes tienen un potencial similar al de la soja, como suplementos proteicos de forrajes de baja calidad como la hoja de olivo o la paja de cereal.

La información acerca del efecto de la inclusión de semillas de leguminosas en la dieta del rumiante sobre la calidad de los productos es escasa. En ganado caprino en lactación se han utilizado dietas en las que el $30 \%$ de su proteína procedía de semillas de altramuz, haba, yero, veza o soja (Ramos-Morales, de la Torre Adarve y Molina Alcaide, 2010a; Ramos-Morales, de la Torre Adarve, Molina Alcaide y Sanz Sampelayo, 2010b). La fermentación ruminal modificaba la composición en aminoácidos de la proteína de las leguminosas estudiadas siendo este efecto diferente para cada una de las semillas. La dieta no modificó la producción de leche aunque algunos componentes nitrogenados de la leche dependían del tipo de semilla incluida en la dieta de los animales y, concretamente, de la composición en aminoácidos de la fracción proteica que no se degrada en el rumen. Estos autores también observaron que la partición del balance de nitrógeno entre la producción de leche y el depósito corporal variaba de- pendiendo de la dieta suministrada a los animales. La inclusión de habas en dietas para cabras en lactación mejora el perfil de ácidos grasos de la leche aumentando su contenido en ácidos grasos insaturados, con propiedades saludables para el consumidor (MolinaAlcaide et al., 2010). La cantidad y calidad de la leche de oveja no se afectaron por la inclusión de garbanzo en su dieta, comparado con la soja (Christodoulou et al., 2005) probablemente porque la concentración de energía y la degradabilidad de la proteína sean similares en soja y garbanzo. El altramuz se ha utilizado con éxito en dietas para vacas de alta producción lechera (Mansbridge y Blake, 1998) y como sustituto de la soja en dietas para ovejas sin efecto sobre la producción de leche o sobre la composición de la misma en proteína o grasa (Masucci et al., 2006).

En cuanto a la influencia de la inclusión de leguminosas en la dieta sobre la calidad de la carne, la información disponible indica que la carne de corderos cuya dieta incluía habas tiene una mayor aceptabilidad que la de corderos alimentados con una dieta que incluía soja (Caballero, Riopérez, Fernández, Marín, y Fernández, 1992). La inclusión de 180-390 g de guisante / kg de dieta no afectó a la calidad de la carne de cordero (Lanza, Bella, Priolo y Fasone, 2003). La sustitución de soja y cebada por garbanzos no afectó a la productividad del cordero (Hadjipanayiotou, 2002; Christodoulou et al., 2005) y aumentó el contenido en ácidos grasos saludables de la carne de cordero (Priolo, Lanza, Galofaro, Fasone y Bella, 2003).

El éxito en el uso de leguminosas grano estriba en formular dietas balanceadas en amino ácidos esenciales siendo una de sus limitaciones el bajo contenido en lisina y aminoácidos azufrados (Vasta, Nudda, Cannas, Lanza y Priolo, 2008). La susceptibilidad del animal a la presencia de compuestos secundarios en leguminosas depende de la especie animal, la dieta, el tiempo en que la alimentación con leguminosas se prolongue o diferencias geográficas en la ecología del rumen. Bampidis y Christodoulou (2011) recomiendan la introducción de $300 \mathrm{~g}$ de semillas de leguminosas / kg de dieta en corderos porque consideran que sus compuestos secundarios se desactivan con la fermentación ruminal.

Actualmente se considera que los compuestos secundarios de leguminosas pueden tener efectos tan beneficiosos como la disminución de parásitos en animales en pastoreo (Hoste et al., 2015) o la de las emisiones de metano, gas con un potente efecto invernadero (Saminathan Mookia, Norhani, Vui Ling Wong y YinWan, 2015). 


\section{NOTAS}

1. Ver Las leguminosas como alimentos funcionales.

\section{BIBLIOGRAFÍA}

Abreu, A., Carulla, J. E., Lascano, C. E., Díaz, T. E, Kreuzer, M. y Hess, H. D. (2004). Effects of Sapindus saponaria fruits on ruminal fermentation and duodenal nitrogen flow of sheep fed a tropical grass diet with and without legume. Journa of Animal Science, 82, pp. 1392-1400.

Aguilera, J. F., Bustos, M. y Molina E. (1992). The degradability of legume seed meals in the rumen: effect of heat treatment. Animal Feed Science and Technology, 36, pp. 101-112. http://dx.doi. org/10.1016/03778401(92)90090S

Arai, S. (2002). Global view on functional foods: Asian perspectives. British Journal of Nutrition, 88, S139-S143. http:// dx.doi.org/10.1079/BJN2002678

Aubry, M. y Boucrot, P. (1986). Etude comparée de la digestion des viciline et lectine radiomarquées de Pisum sativum chez le rat. Annals in Nutrition and Metabolism, 30, pp. 175-182. http:// dx.doi.org/10.1159/000177191

Bäckhed, F., Ley, R. E., Sonnenburg, J. L., Peterson, D. A. y Gordon, J. I. (2005). Host-bacterial mutualism in the human intestine. Science, 307, pp. 19151920. http://dx.doi.org/10.1126/science. 1104816

Bampidis V. A. y Christodoulou, V. (2011). Chickpeas (Cicer arietinum L.) in animal nutrition: A review. Animal Feed Science and Technology, 168, pp. 1-20. http://dx.doi.org/10.1016/j.anifeedsci.2011.04.098

Batterham, E. S., Andersen, L. M., Lowe, R. F. y Darnell, R. E. (1986). Nutritional value of lupin (Lupinus albus)-seed meal for growing pigs: availability of lysine, effect of autoclaving and net energy content. British Journal of $\mathrm{Nu}$ trition, 56, pp. 645-659. http://dx.doi. org/10.1079/BJN19860145

Benchaar, C., Vernay, M., Bayourthe, C. y Moncoulon, R. (1994). Effect of extrusion of whole horse beanson protein digestion and amino acid absorption in dairy cows. Journal of Dairy Science, 77, pp. 1360-1371. http://dx.doi. org/10.3168/jds.S00220302(94)770752
2. Estos aspectos se tratan más en extenso en el arto de Alfonso Clemente incluido en este mismo número.

Benevenga, N. J., Gahl, M. J. y Blemings, K. P. (1993). Role of protein-synthesis in amino-acid catabolism. Journal of $\mathrm{Nu}$ trition, 123, pp. 332-336.

Boulter, D., Gatehouse, A. M. R., Gatehouse, J. A. y Cox, R. B. (1985). Plant protection using cow pea trypsin inhibitor - esp. used against heliothis pests on cotton, etc. Patent Number(s): EP135343-A1; EP135343-A ; US4640836-A

Bressani, R. y Elias, L. G. (1980). Nutritional value of legume crops for humans and animals. En: Summerfield, R. J. y Bunting, A. H. (eds.) Advances in Legume Science. Surrey. England: Royal Botanic Gardens, pp. 135-155.

Burkitt, D. P., Walker, A. R. y Painter, N. S (1972). Effect of dietary fibre on stools and the transit-times, and its role in the causation of disease. Lancet, 2, pp. 1408-1412. http://dx.doi.org/10.1016/ S01406736(72)929741

Caballero, R. (1999). Castile-La Mancha: a once traditional and integrated cerealsheep farming system under change. American Journal of Alternative Agriculture, 14, pp. 188-192. http://dx.doi. org/10.1017/S0889189300008389

Caballero, R., Riopérez, J., Fernández, E., Marín, M. T. y Fernández, C. (1992). A note on the use of field beans (Vicia $f a b a)$ in lamb finishing diets. Animal Production, 54, pp. 441-444. http://dx.doi. org/10.1017/S0003356100020900

Caligari, S., Chiesa, G., Johnson, S. K., Camisassi, D., Gilio, D., Marchesi, M., Parolini, C., Rubio, L. A. y Sirtori, C.R. (2006). Lupin (Lupinus albus) protein isolate (L-ISO) has adequate nutritional value and reduces large intestinal weight in rats after restricted and ad libitum feeding. Annals of Nutrition and Metabolism, 50, pp. 528-537. http://dx.doi. org/10.1159/000098145

Christodoulou, V., Bampidis, V. A., Hu cko, B., Ploumi, K., lliadis, C., Robinson, P. H. y Mud'rík, Z. (2005). Nutritional value of chickpeas in rations of lactating ewes and growing lambs. Animal Feed Science and Technology, 118, pp. 229-241. http://dx.doi. org/10.1016/j.anifeedsci.2004.10.017
Christou, P., Capell, T., Kohli, A., Gatehouse, J. A. y Gatehouse, A. M. R. (2006). Recent developments and future prospects in insect pest control in transgenic crops. Trends in Plant Science, 11, 6, pp. 302-308. http:// dx.doi.org/10.1016/j.tplants.2006.04.001

Clemente, C. y Arqués, M. C. (2014). Bowman-Birk inhibitors from legumes as colorectal chemopreventive agents. World Journal of Gastroenterology, 20, pp. 10305-10315. http://dx.doi. org/10.3748/wjg.v20.i30.10305

Cuadrado, C., Grant, G., Rubio, L. A., Múzquiz, M., Bardocz, S. y Pusztai, A. (2002). Nutritional utilization by the rat of diets based in lentil (Lens culinaris) seed meal or its fractions. Journal of Agricultural and Food Chemistry, 50, pp. 4371-4376. http://dx.doi.org/10.1021/jf020014j

Cummings, J. H. (1981). Dietary fiber. British Medical Bulletin, 37, pp. 65-70.

D'Mello, J. P. F. (1992). Chemical constraints to the use of tropical legumes in animal nutrition. Animal Feed Science and Technology, 38, pp. 237-261. http://dx.doi. org/10.1016/03778401(92)90105F

Dréau, D., Lallès, J. P., Philouze-Rome, V., Toullec, R. y Salmon, H. (1994). Local and systemic immune responses to soybean protein ingestion in early-weaned pigs. Journal of Animal Science, 72, pp. 2090-2098.

Ewen, S. W. B. y Pusztai, A. (1999). Effect of diets containing genetically modified potatoes expressing Galanthus nivalis lectin on rat small intestine. Lancet, 354, pp. 1353-1354. http://dx.doi. org/10.1016/S01406736(98)058607

Flis, M., Sobotka, W., Purwin, C. y Zdunczyk, Z. (1999). Nutritional value of diets containing field bean (Vicia faba L.) seeds with high or low proanthocyanidin levels for pig. Journal of Animal and Feed Sciences, 8, pp. 171-180.

Fuller, R. (1992). Probiotics. The Scientific Basis. London: Chapman \& Hall. http:// dx.doi.org/10.1007/9789401123648

Furda, I. y Brine, C. J. (1990). New Developments in Dietary Fibre. London, New York: Plenum Press. http://dx.doi. org/10.1007/9781468457841 
Gatel, F. (1992). Dietary factors affecting protein digestibility in pigs. En: $1 S T$ International Symposium on Nitrogen Flow in Pig Production and Environmental Consequences. Wageningen, Netherlands, pp 70-89.

Gelvin A. A., Lardy, G. P., Soto-Navarro, S. A., Landblom, D. G. y Caton, J. S. (2004). Effect of field pea-based creep feed on intake, digestibility, ruminal fermentation, and performance by nursing calves grazing native range in western North Dakota. Journal of Animal Science, 82, pp. 3589-3599.

Goelema, J. O., Spreeuwenberg, M. A. M., Hof, G., van der Poel, A. F. B. y Tamminga, S. (1998). Effect of pressure toasting on the rumen degradability and intestinal digestibility of whole and broken peas, lupins and faba feans and a mixture of these feedstuffs. Animal Feed Science and Technology, 76, pp. 35-50. http://dx.doi.org/10.1016/ S03778401(98)002120

González, J. y Andrés, S. (2003). Rumen degradability of some feed legume seeds. Animal Research, 52, pp. 17-25. http:// dx.doi.org/10.1051/animres:2003003

Hadjipanayiotou, M. (2002). Replacement of soybean meal and barley grain by chickpeas in lamb and kid fattening diets. Animal Feed Science and Technology, 96, pp. 103-109. http://dx.doi. org/10.1016/S03778401(01)00339X

Hoste H., Torres-Acosta, J. F. J., SandovalCastro, C. A., Mueller-Harvey, I., Sotiraki, S., Louvandini, H., Thamsborg, S. M. y Terrill, T. H. (2015). Tannin containing legumes as a model for nutraceuticals against digestive parasites in livestock. Veterinary Parasitology, 212, pp. 5-17. http://dx.doi.org/10.1016/j. vetpar.2015.06.026

Imberechts, H., Degreve, H. y Lintermans, P. (1992). The pathogenesis of edema disease in pigs - a review. Veterinary Microbiology, 31, pp. 221-233. http://dx.doi. org/10.1016/03781135(92)90080D

Jansman, A. J. M. (1993). Tannins in feedstuffs for simple stomached animals. Nutritional Research Reviews, 6, pp. 209-236. http://dx.doi.org/10.1079/ NRR19930013

Jansman, A. J. M., Huisman, J. y van der Poel, A. F. B. (1993). Ileal and faecal digestibility in piglets of field beans (Vicia faba L.) varying in tannin content. Animal Feed Science and Tech- nology, 42, pp. 83-96. http://dx.doi. org/10.1016/03778401(93)90025F

Jansman, A. J. M., Verstegen, M. W. A., Huisman, J. y van den Berg, J. W. O. (1995). Effects of hulls of faba beans (Vicia faba L.) with a low or high content of condensed tannins on the apparent ileal and fecal digestibility of nutrients and the excretion of endogenous protein in ileal digesta and feces of pigs. Journal of Animal Science, 73, pp. 118-127.

Jezierny, D., Mosenthin, R., Sauer, N., Roth, S., Piepho, H.-P., Rademacher, M. Y Eklund, M. (2011). Chemical composition and standardised ileal digestibilities of crude protein and amino acids in grain legumes for growing pigs. Livestock Science, 138, pp. 229-243. http:// dx.doi.org/10.1016/j.livsci.2010.12.024

Kennedy, A. R. (1993). Cancer prevention by protease inhibitors. Preventive medicine, 22, pp. 796-811. http://dx.doi. org/10.1006/pmed.1993.1073

Kumar, V., Sinha, A. K., Makkar, H. P. S. y Becker, K. (2010). Dietary roles of phytate and phytase in human nutrition: $\mathrm{A}$ review. Food Chemistry, 120, pp. 945959. http://dx.doi.org/10.1016/j.foodchem.2009.11.052

Lallès, J. P., Dréau, D., Féménia, F., Parodi, A. L. y Toulec, R. (1996). Feeding heated soyabean flour increases the density of $B$ and $T$ lymphocytes in the small intestine of calves. Veterinary Immunological Immunopathology, 52, pp. 105-115. http://dx.doi. org/10.1016/01652427(95)055347

Lanza, M., Bella, M., Priolo, A. y Fasone, V. (2003). Peas (Pisum sativum L.) as an alternative protein source in lamb diets: growth performances, and carcass and meat quality. Small Ruminant Research, 47, pp. 63-68. http://dx.doi. org/10.1016/S09214488(02)002444

Liener, I. E. y Kakade, M. L. (1980). Protease inhibitors. In: Liener, I. E. (ed.) Toxic Constituents of Plant Foodstuffs. New York: Academic Press, pp. 7-71. http://dx.doi.org/10.1016/ B9780124499454.500051 / http://dx.doi. org/10.1016/B9780124499454.500154

Liener, I. E., Sharon, N. y Lis, H. (1986). The Lectins: Properties, Fuctions and Applications in Biology and Medicine. New York: Academic Press.

Loe, E. R., Bauer, M. L., Lardy, G. P., Caton, J. S. y Berg, P. T. (2004). Field pea (Pisum sativum) inclusion in cornbased lamb finishing diets. Small
Ruminant Research, 53, pp. 39-45. http://dx.doi.org/10.1016/j.smallrumres.2003.08.020

Lovati, M. R., Manzoni, C., Corsini, A., Granata, A., Frattini, R., Fumagalli, R. y Sirtori, C. R. (1992). Low-density-lipoprotein receptor activity is modulated by soybean globulins in cell-culture. Journal of Nutrition, 122, pp. 1971-1978.

Mansbridge, R. J. y Blake, J. S. (1998). The effect of feeding different protein sources on intake, milk yield, milk composition and live weight in high yielding Holstein cows. Proceedings of the British Society of Animal Production, 202.

Marquardt, R. R., Campbell, L. D. y Ward, T. (1976). Studies with Chicks on the Growth Depressing Factor(s) in Faba Beans (Vicia faba L. var. minor). Journal of Nutrition, 106, pp. 275-284.

Masucci, F., Di Francia, A., Romano, R., Maresca di Serracapriola, M. T., Lambiase, G., Varricchio, M. L. y Proto, V. (2006). Effect of Lupinus albus as protein supplement on yield, constituents, clotting properties and fatty acid composition in ewes' milk. Small Ruminant Research, 65, pp. 251-259. http://dx.doi. org/10.1016/j.smallrumres.2005.06.023

Mathew, A. G., Sutton, A. L., Scheidt, A. B., Patterson, J. A., Kelly, D. T. y Meyerholtz, K. A. (1993). Effect of galactan on selected microbial-populations and ph and volatile fatty-acids in the ileum of the weanling pig. Journal of Animal Science, 71, pp. 1503-1509.

Modler, H. W., Mckellar, R. C. y Yaguchi, M. (1990). Bifidobacteria and bifidogenic factors. Canadian Institute of Food Science and Technology Journal, 23, pp. 29-41. http://dx.doi.org/10.1016/ S03155463(90)701976

Molina-Alcaide E., Morales-García, E. Y., Martín-García, A. I., Ben Salem, H., Nefzaoui, A. y Sanz-Sampelayo, M. R. (2010). Effects of partial replacement of concentrate with feed blocks on nutrient utilization, microbial $\mathrm{N}$ flow, and milk yield and composition in goats. Journal of Dairy Science, 93, pp. 2076-2087. http://dx.doi.org/10.3168/ jds. 20092628

Murphy S. R. y McNiven, M. A. (1994). Raw or roasted lupin supplementation of grass silage diets for beef steers. Animal Feed Science and Technology, 46, pp. 23-35. http://dx.doi. org/10.1016/03778401(94)900620 
Nielsen, S. S. (1991). Digestibility of legume proteins. Food Technology, 45, 112.

Poel, van der, A. F. B., Dellaert, L. M., Norel, A. y Helpster, J. P. F. G. (1992). The digestibility in piglets of faba bean (Vicia faba L.) as affected by breeding towards the absence of condensed tannins. British Journal of Nutrition, 68, pp. 793-800.

Priolo, A., Lanza, M., Galofaro, V., Fasone, V. y Bella, M. (2003). Partially or totally replacing soybean meal and maize by chickpeas in lamb diets: intramuscular fatty acid composition. Animal Feed Science and Technology, 108, pp. 215-221. http://dx.doi.org/10.1016/ S03778401(03)001664

Pusztai, A. (1998). Biological effects of plant lectins on the gut: Metabolic consequences and applications. En: Effects of antinutrients on the nutritional value of legume diets. Cost Action 98, Luxembourg: Office for Oficial Publications of the European Communnities.

Pusztai, A., Croy, R. R. D., Grant, G. y Stewart, J. C. (1983). Seed lectins: distributio location and biological role. En: Daussant, J. Mosse, J. y Vaugham, J. (eds.) Seed Proteins. London: Academic Press, pp. 53-81.

Pusztai, A., Grant, G., King, T. P. y Clarke, E. M. W. (1990). Chemical probiosis. En: Haresign, W. y Cole, D. J. A. (eds.) Recent Advances in Animal Nutrition. London: Butterworths, pp. 47-60. http://dx.doi. org/10.1016/b9780408041508.500098

Pusztai, A., Grant, G., Spencer, R. J., Duguid, T. J., Brown, D. S., Ewen, S. W. B., Peumans, W. J., Vandamme, E. J. M. y Bardocz, S. (1993). Kidney bean lectin-induced $E$. coli overgrowth in the small-intestine is blocked by GNA, a mannose-specific lectin. Journal of Applied Bacteriology, 75, pp. 360-368. http://dx.doi. org/10.1111/j.13652672.1993.tb02788.x

Pusztai, A., Kocsis, G., Grant, G., Ewen, S. W. B. y Bardocz, S. (1993). Use of lectins for targeting drug-microparticle complexes to selected sites in the gastrointestinal tract and facilitating their transport into the systemic circulation. Journal of Cellular Biochemistry, Suppl. 17A, p. 383.

Ramos-Morales, E., Sanz-Sampelayo, M. R. y Molina-Alcaide, E. (2010a). Nutritive evaluation of legume seeds for ruminant feeding. Journal of Animal Physiology and Animal Nutrition, 94, pp. 55-64. http://dx.doi.org/10.1111/ j.14390396.2008.00881.x
Ramos-Morales, E., de la Torre Adarve, G., Molina Alcaide, E. y Sanz Sampelayo, M. R. (2010b). Nitrogen and energy utilization in lactating dairy goats fed diets with different legume seeds. Journal of Animal Physiology and Animal Nutrition, 94, pp. 659-664. http://dx.doi. org/10.1111/j.14390396.2009.00953.x

Reddy, N. R., Sathie, S. K. y Salunkhe, D. K. (1982). Phytates in legumes and cereals. Advances in Food Research, 28, pp. 1-92. http://dx.doi.org/10.1016/ S00652628(08)60110X

Roberts, T., Wilson, J., Guthrie, A., Cookson, K., Vancraeynest, D., Schaeffer, J., Moody, R. y Clark, S. (2015). New issues and science in broiler chicken intestinal health: intestinal microbial composition, shifts, and impacts. World's Poultry Science Journal, 71, pp. 259-269. http://dx.doi.org/10.1017/ S0043933915000276

Romero, J. y Ryan, D. S. (1978). Susceptibility of major storage protein of bean, Phaseolus vulgaris, to in vitro enzymatic-hydrolysis. Journal of Agricultural and Food Chemistry, 26, pp. 784-788. http://dx.doi.org/10.1021/jf60218a037

Rubio, L. A. (2000a). Physiological effects of legume storage proteins. Nutrition Abstracts and Reviews, 70, pp. 197-204.

Rubio, L. A. (2000b). Aspectos nutricionales relacionados con alimentos producidos a partir de organismos genéticamente modificados. En 11은 Symposium Phytoma-España: La Biotecnología y la Sanidad de los Cultivos. Phytoma-España, 120, pp. 93-94.

Rubio, L. A., Brenes, A. y Castaño, M (1989). Histological alterations to the pancreas and the intestinal tract produced by raw faba bean (Vicia faba L.) diets in growing chicks. British Poultry Science, 30, pp. 15-28. http://dx.doi. org/10.1080/00071668908417129

Rubio, L. A., Brenes, A. y Castaño, M. (1990). The utilization of raw and autoclaved faba beans (Vicia faba L.) and faba bean fractions in diets for growing chickens. British Journal of Nutrition, 63, pp. 419-433. http://dx.doi.org/10.1079/ BJN19900130

Rubio, L. A., Brenes, A., Cutuli, M. y Setién, I. (1998). Lactobacilli counts in crop, ileum and caecum of growing broiler chickens fed practical diets containing whole or dehulled sweet lupin (Lupinus angustifolius) seed meal. British Poultry
Science, 39, pp. 354-359. http://dx.doi. org/10.1080/00071669888890

Rubio, L. A., Clemente, A., Ruiz, R., Marín, M. C. y Jiménez, E. (2007). Aspectos novedosos en la Nutrición Funcional. En: AA.VV. Vigilancia Tecnológica (Alimentación Funcional), Sevilla: Agencia de Innovación y Desarrollo de Andalucía, Consejería de Innovación, Ciencia y Empresa, Junta de Andalucía, pp. 51-53.

Rubio, L. A., Grant, G., Bardocz, S., Dewey, P. y Pusztai, A. (1991). Nutritional response of growing rats to faba beans (Vicia faba) and faba bean fractions. British Journal of Nutrition, 66, pp. 533-542. http://dx.doi.org/10.1079/ BJN19910053

Rubio, L. A., Grant, G., Cavallé, C., MartínezAragón, A. y Pusztai, A. (1994). High in vivo (rat) digestibility of faba bean (Vicia faba), lupin (Lupinus angustifolius) and soybean (Glycine max) soluble globulins. Journal of the Science of Food and Agriculture, 66, pp. 289-292. http:// dx.doi.org/10.1002/jsfa.2740660305

Rubio, L. A., Grant, G., Daguid, T., Brown, D., Bardocz, S. y Pusztai, A. (1998). The nutritional utilization by rats of chickpea (Cicer arietinum) meal and its isolated globulin proteins is poorer than that of defatted soybean or lactalbumin. Journal of Nutrition, 128, pp. 1042-1047. http:// dx.doi.org/10.1002/(SICI)10970010(19 9902)79:2<187::AIDJSFA177>3.0.CO;29

Rubio, L. A., Grant, G., Daguid, T., Brown, D. y Pusztai, A. (1999). Organ relative weights and plasma amino acid concentrations in rats fed diets based in legume (faba bean, lupin, chickpea, soybean) seed meals or their fractions. Journal of the Science of Food and Agriculture, 79, pp. 187-194.

Rubio, L. A., Grant, G., Scislowsky, P., Brown, D., Annand, M. y Pusztai, A. (1995). The utilization of lupin (Lupinus angustifolius) and faba bean globulins by rats is poorer than of soybean globulins or lactalbumin but the nutritional value of lupin seed meal is lower only than that of lactalbumin. Journal of Nutrition, 125 , pp. 2145-2155.

Rubio, L. A., Grant, G., Spencer, R. y Pusztai, A. (1995). The effects of feeding lupin (Lupinus angustifolius) seed meal or its insoluble fraction on the intestinal microflora population in the rat. Microbial Ecology in Health and Disease, 8, pp. 101-105. http://dx.doi. org/10.3109/08910609509140086 
Rubio, L. A., Múzquiz, M., Burbano, C., Cuadrado, C. y Pedrosa, M. M. (2002). High apparent ileal digestibility of amino acids in raw or germinated faba bean(Vicia faba) and chickpea- (Cicer arietinum) based diets for rats. Journal of the Science of Food and Agriculture, 82, pp. 1702-1717. http://dx.doi.org/10.1002/ jsfa. 1228

Rubio, L. A. y Peinado, M. J. (2015). Replacement of soybean meal with lupin or chickpea seed meal in diets for fattening Iberian pigs promotes a healthier ileal microbiota composition. Advances in Microbiology, 4, pp. 498-503. http:// dx.doi.org/10.4236/aim.2014.49055

Rubio, L. A., Rodríguez, J., Fernández, C. y Crespo, J. F. (2004). Storage proteins: physiological and antigenic effects. En Muzquiz, M., Hill, G. D., Cuadrado, C., Pedrosa, M. M y Burbano, C. (eds.) Recent advances of research in antinutritional factors in legume seeds and oilseeds. Proceedings of the fourth international workshop on antinutritional factors in legume seeds and oilseeds, Wageningen Academic Publishers, pp. 159-176.

Rubio, L. A. y Seiquer, I. (2002). Transport of amino acids from in vitro digested legume proteins or casein in Caco-2 cell cultures. Journal of Agricultural and Food Chemistry, 50, pp. 5202-5206. http://dx.doi.org/10.1021/jf0201778

Salyers, A. A. (1979). Energy-sources of major intestinal fermentative anaerobes. American Journal of Clinical Nutrition, 32, pp. 158-163.

Salminen, S., Bouley, C., Boutron-Ruault, M.C., Cummings, J. H., Franck, A., Gibson, G. R., Isolauri, E., Mores, M. C., Roberfroid, M. y Rowland, I. (1998). Functional Food Science in Europe. British Journal of $\mathrm{Nu}$ trition, 80, Suppl 1, pp. S147-S171. http:// dx.doi.org/10.1079/BJN19980108

Saminathan Mookia, Ch. Ch. S., Norhani, A., Vui Ling Wong, C. M. y YinWan, H. (2015). Effects of condensed tannin fractions of different molecular weights from a Leucaena leucocephala hybrid on in vitro methane production and rumen fermentation. Journal of the Science of Food and Agriculture, 95, pp. 2742-2749. http:// dx.doi.org/10.1002/jsfa.7016
Shamsuddin, A. M. y Ullah, A. (1989). Inositol hexaphosphate inhibits large intestinal cancer in $\mathrm{f344}$ rats 5 months after induction by azoxymethane. Carcinogenesis, 10, pp. 625-626. http://dx.doi. org/10.1093/carcin/10.3.625

Shamsuddin, A. M. (1995). Inositol phosphates have novel anticancer function. Journal of Nutrition, 125, S725-S732.

Selle, P. H., Cowieson, A. J., Cowieson, N. P. y Ravindran, V. (2012). Protein-phytate interactions in pig and poultry nutrition: a reappraisal. Nutrition Research Reviews, 25, pp. 1-17. http://dx.doi. org/10.1017/S0954422411000151

Sgarbieri, V. C. y Whitaker, J. R. (1982). Physical, chemical, and nutritional properties of common bean (Phaseolus) proteins. Advances in Food Research, 28, pp. 93-166. http://dx.doi.org/10.1016/ S00652628(08)601111

Soto-Navarro, S. A., Williams, G. H., Bauer, M. L., Lardy, G. P., Landblom, D. G. y Caton, J. S. (2004). Effect of field pea replacement level on intake and digestion in beef steers fed by-product-based medium-concentrate diets. Journal of Animal Science, 82, pp. 1855-1862.

Treviño, J., Centeno, C., Brenes, A., Yuste, P. y Rubio, L. A. (1990). Effect of dietary oligosaccharides on the digestion of pea (Pisum sativum L.) starch by growing chicks. Animal Feed Science and Technology, 30, pp. 313-319. http://dx.doi. org/10.1016/03778401(90)90021Y

Ullah, A. y Shamsuddin, A. M. (1990). Dosedependent inhibition of large intestinal cancer by inositol hexaphosphate in f344 rats. Carcinogenesis, 11, pp. 22192222. http://dx.doi.org/10.1093/car$\operatorname{cin} / 11.12 .2219$

Utrilla, M. P., Peinado, M. J., Ruiz, R., Rodríguez-Nogales, A., Algieri, F., RodríguezCabezas, M. E., Clemente, A., Gálvez, J. y Rubio, L. A. (2015). Pea (Pisum sativum L.) seed albumin extracts show antiinflammatory effect in a DSS model of mouse colitis. Molecular Nutrition and Food Research, 59, pp. 807-819. http:// dx.doi.org/10.1002/mnfr.201400630

Vasta, V., Nudda, A., Cannas, A., Lanza, M. y Priolo, A. (2008). Alternative feed re- sources and their effects on the quality of meat and milk from small ruminants. Review. Animal Feed Science and Technology, 147, pp. 223-246. http://dx.doi. org/10.1016/j.anifeedsci.2007.09.020

Voisin, A. S., Guéguen, J., Huyghe, C., Jeuffroy, M. H., Magrini, M. B., Meynard, J. M., Mougel, C., Pellerin, S. y Pelzer, E. (2014). Legumes for feed, food, biomaterials and bioenergy in Europe: a review. Agronomy for Sustainable Development, 34, pp. 361-380. http://dx.doi. org/10.1007/s135930130189y

Wiggins, H. S. (1984). Nutritional-value of sugars and related-compounds undigested in the small gut. Proceedings of the Nutrition Society, 43, pp. 69-75. http:// dx.doi.org/10.1079/PNS19840029

Wilkins R. J. y Jones, R. (2000). Alternative home-grown protein sources for ruminants in the United Kingdom. Review article. Animal Feed Science and Technology, 85, pp. 23-32. http://dx.doi. org/10.1016/S03778401(00)001401

Wilson, B. J., Bentley, H. y McNab, J. M. (1972a). Trypsin-inhibitor activity in field bean (Vicia faba). Journal of the Science of Food and Agriculture, 23, pp. 679-684. http://dx.doi.org/10.1002/ jsfa. 2740230602

Wilson, B. J., McNab, J. M. y Bentley, H. (1972b). Effect on chick growth of a trypsin-inhibitor isolate from field bean (Vicia faba). British Poultry Science, 13, pp. 521-523. http://dx.doi. org/10.1080/00071667208415979

Yáñez-Ruiz, D. R., Martín-García, A. I., Weisbjerg, M. R., Hvelplund, T. y Molina-Alcaide, E. (2009). A comparison of different legume seeds as protein supplement to optimise the use of low quality forages by ruminants. Archives of Animal Nutrition, 63, pp. 39-55. http://dx.doi. org/10.1080/17450390802611479

Yáñez Ruiz, D. R., Moumen, A. y Molina, E. (2004). Comparative studies on microbial protein synthesis in the rumen of goats and sheep. Journal of Animal and Feed Sciences, 13, Suppl. 1, pp. 251-254. 